\title{
Determining optimal location and size of capacitors in radial distribution networks using moth swarm algorithm
}

\author{
Thanh Long Duong1, Thuan Thanh Nguyen ${ }^{2}$, Van-Duc Phan ${ }^{3}$, Thang Trung Nguyen ${ }^{4}$ \\ ${ }^{1,2}$ Faculty of Electrical Engineering Technology, Industrial University of Ho Chi Minh City, Vietnam \\ ${ }^{3}$ Faculty of Automobile Technology, Van Lang University, Vietnam \\ ${ }^{4}$ Faculty of Electrical and Electronics Engineering, Ton Duc Thang University, Vietnam
}

\begin{tabular}{l} 
Article Info \\
\hline Article history: \\
Received Feb 14, 2020 \\
Revised Mar 14, 2020 \\
Accepted Mar 28, 2020 \\
\hline Keywords: \\
Modified moth swarm \\
algorithm \\
Optimal location \\
Optimal size \\
Radial distribution network \\
\hline
\end{tabular}

\begin{abstract}
In this study, the problem of optimal capacitor location and size determination (OCLSD) in radial distribution networks for reducing losses is unraveled by moth swarm algorithm (MSA). MSA is one of the most powerful meta-heuristic algorithm that is taken from the inspiration of the food source finding behavior of moths. Four study cases of installing different numbers of capacitors in the 15-bus radial distribution test system including two, three, four and five capacitors areemployed to run the applied MSA for an investigation of behavior and assessment of performances. Power loss and the improvement of voltage profile obtained by MSA are compared with those fromother methods. As a result, it can be concluded that MSA can give a good truthful and effective solution method for OCLSD problem.
\end{abstract}

Copyright $\odot$ 2020Institute of Advanced Engineering and Science. All rights reserved.

\section{Corresponding Author:}

Thang Trung Nguyen,

Power System Optimization Research Group,

Faculty of Electrical and Electronics Engineering, Ton Duc Thang University,

19 Nguyen HuuTho street, Tan Phong ward, District 7, Ho Chi Minh City, Viet Nam.

Email: nguyentrungthang@tdtu.edu.vn

NOMENCLATURE
$C r$
$C I, M I$
Dim
$g$
$G P$
$G r 1, G r 2, G r 3$
$I_{c}$
$I_{c}^{\max }$
$L D$
Levy1, Levy2
$N b$
$N_{b u s}$
$N_{C}$
$P L$
$Q_{\min ,}, Q_{\max }$
$R 1, R 2, R 3, R 4, R 5$
$R_{c}$
$V_{\min }, V_{\max }$
$X_{r 1}, X_{r 2}, X_{r 3}, X_{r 4}, X_{r 5}, X_{r 6}$
$X_{b e s t}, X_{G b e s t}$

The number of randomly selected control variables among Dim variables

The current iteration and the maximum iteration

The number of control variables of each solution

The $g$ th variable of each solution

Source power at bus 1

The number of solutions in group 1, group 2 and group 3

Current magnitude of the $c t h$ branch

The maximum current magnitude of each branch

Total load demand

Two Lévy flight distributions

Number of branches

Number of buses

Number of capacitors

Total active power losses

The minimum and maximum rated power of capacitor

Random numbers distributed uniformly within the interval $[0,1]$

Resistor of the $c t h$ branch

The minimum and maximum rated voltage of bus

Randomly selected solutions from solutions

The best solution in group 1, group 2 and all groups 


\section{INTRODUCTION}

In a power system, lines have one of the important elements in transmitting electric energy from power plants to industrial zones and house holds. There are commonly two-line types such as transmission lines and distribution lines. Here, transmission lines are managed by Transmission Company while other ones are controlled by Electrical Company. However, current running on distribution linesis higher than that of transmission lines because of its low voltage, leading to higher power lossesas well as voltage regulation. Also, distribution lines are developing large and being extended. A solution to the mentioned difficulties can be solved by installing distributed generators [1] or adding capacitors at proper locations [2]. In this paper, we only focus on finding the best location and the most appropriate size of capacitors in radial distribution networks. The strategic mission of the considered OCLSD problem is to determine the most suitable location and sizing of capacitors at buses in a radial distribution system in order to decrease power losses, improve the voltage profile, power factor and avoid overloadas presented in a highly efficient method (HEM) [2]. The OCLSD problem has received more attention from researchers and many methods have been proposed. In solving OCLSD problem, a manner implemented in methods has been doneintwo ways. One is to determine the optimal locations for capacitor placementat candidate busesfirstly and then the optimal sizing of capacitors is calculated. Another is simultaneously done a determination both the optimal location and sizing of capacitors. References [3-5] have used a fuzzy techniqueto find the most suitable positions for capacitor placement while real coded genetic algorithm (RCGA) [3], particle swarm optimization (PSO) [4] and differential evolution (DE) [5] and multi agent PSO (MAPSO) [5] have been applied for sizing of capacitors. Similar to methods above, references [6-11] and [12] have also located the candidate buses by using loss sensitivity factor (LSF) and then the optimal capacitor sizes have been done bytime-varying inertia weighting PSO (TVIWPSO) [6], maximum load-ability index (MLI) [7], genetic algorithm (GA) [8], inertia weighting PSO (IWPSO) [9], ant colony optimization (ACO) algorithm [10], modified harmony algorithm (MHA) [11] and artificial bee colony algorithm (ABC) [12]. Dissimilar to the previous methods, teaching learning based optimization (TLBO) [13], hybrid method of chaotic search, opposition-based learning, DE and quantum mechanics (HCODEQ) [14], particle swarm optimization approaches (PSOs) [15] and flower pollination algorithm (FPA) [16] have solved such OCLSD problem by considering locations and size of capacitor as control variables of each solution. On the other hand, voltage enhancement can be reached by using wind turbines and photovoltaic systems [17, 18], network reconfiguration [19-21], and distributed generators [22]. In this paper, MSA is applied to OCLSD problem. The results obtained from MSA are competed with the lately reported results. Moth swarm algorithm (MSA) was evolved by Al-Attar Ali Mohamed in 2017 [23] and employed for solvingoptimization problems such as combined economic and emission dispatch [24] and image segmentation [25, 26]. In summary, the novelty and contribution of the paperare as follows:

- The first application of MSA for different case of installing capacitors in radial distribution network

- Demonstration of the effectiveness of the number of capacitors for voltage enhancement

- Show a detail of MSA procedure for updating new solutions

- Successfully apply MSA for solving OCLSD problem

- MSA can reach higher quality solutions than other ones.

\section{MODEL OF THE OCLSD PROBLEM}

\subsection{Objective function}

Connecting series capacitors or parallel capacitors to the buses of distribution system can significantly reduce total active power losses as well as enhance to the operation stability of the power system. So, minimizing total active power losses $(P L)$ is a key duty in addressing OCLSD problem. Its mathematical formula is given by

$$
\text { Minimize } P L=\sum_{c=1}^{N b} I_{c}^{2} \times R_{c}
$$

\subsection{Constraints}

\subsubsection{Constraints of balancing power system}

In distribution system, sum of total load demandand active power lossesin lines must be equal to generation power as follows:

$$
G P=L D+P L
$$




\subsubsection{The voltage restriction}

The voltage at buses is limited by its lower bound and upper bound below:

$$
V_{\min } \leq V_{i} \leq V_{\max } ; i=1, \ldots, N_{\text {bus }}
$$

\subsubsection{Capacitor size restriction}

Selecting size of capacitors for connecting to distribution systemcan reduce power loss or lead to over compensation. Such over compensation not only make power loss extra but also partly impacts on the stability of the system. In this paper, capacitors' size and location are selected to be control variables mean while size is a continuous variable but location is a discrete variable. Size of capacitor must be restricted by the minimum and maximum rated power of capacitor as the following in equality:

$$
Q_{\min } \leq Q_{k} \leq Q_{\max } ; k=1, \ldots, N_{c}
$$

\subsubsection{Restriction of branch current}

The current running on branchesis equal or smaller than the maximum current of conductor that can be subjected. It is presented as in (5),

$$
\left|I_{c}\right| \leq I_{c}^{\max } ; c=1, \ldots, N b
$$

\section{METHOD}

\subsection{Moth swarm algorithm}

In MSA [23], the optimal solution of the considered problem related to a light source of the moon is considered as thebest moth swarm position and its fitness is the luminescence intensity of the moon. From aninitial moths in population $G r$, theyare assigned three groups with $G r 1, G r 2$ and $G r 3$ by basing on their calculated fitness. In which, moths in Grl are called Path finders that take on finding the light sources to direct the swarm, those from Gr2 are named Prospectors that find the food according to the positions determined by Pathfinders and those from the last group are called on lookers that exploit the food source found by Prospectors. The whole operation of these groups has been respectively implemented in three phases below:

\subsubsection{Reconnaissance phase:}

In the first phase, three popular techniques such as the mutation, adaptive crossover and selection techniques are used for updating new positions of Pathfinders to avoid falling into local search zones. The formulas of these techniques are formed as shown in (6), (7) and (8) respectively.

$$
\begin{aligned}
& S_{s}=X_{r 1}+\text { Levy1. }\left(X_{r 2}-X_{r 3}\right)+\text { Levy2. }\left(X_{r 4}-X_{r 5}\right) ; s \in\left\{1, \ldots, G r_{1}\right\} \\
& Z_{s, g}=\left\{\begin{array}{l}
X_{s, g} \text { if } g \in C r \\
S_{s, g} \text { if } g \notin C r
\end{array} ; g=1, \ldots,\right. \text { Dim } \\
& X_{s}=\left\{\begin{array}{l}
X_{s} \text { if Fitness }\left(Z_{s}\right) \geq \operatorname{Fitness}\left(X_{s}\right) \\
Z_{s} \text { if Fitness }\left(Z_{s}\right)<\text { Fitness }\left(X_{s}\right)
\end{array}\right.
\end{aligned}
$$

For implementing the work in the transverse orientation phase, $X_{\text {Light }}$ with $G r$ solutions areestablished. Each solutionin $X_{\text {Light }}$ is randomly selected from the kept solutions of $\mathrm{Gr}$ dependent on the probability value of solutions $P_{s}$. This probability value is given by,

$$
P_{s}=\frac{\text { Fit }_{s}}{\sum_{s=1}^{G r} F i t_{s}}
$$

where $\mathrm{Fit}_{s}$ is the luminescence intensity factor of each solution $s$ it is calculated from the objective function value Fitness $_{s}$ as presented in (10). 


$$
\text { Fit }_{s}=\left\{\begin{array}{l}
\frac{1}{1+\text { Fitness }_{s}} \text { for Fitness } \\
1+\text { Fitness }_{s} \text { for } \text { Fitness }_{s}<0
\end{array}\right.
$$

\subsubsection{Transverse orientation phase:}

From information about the luminescence intensityshared by Pathfinders, Prospectors fly according to a logarithmic spiral pathto update their position. The process for updating Prospector'sposition is shown as (11),

$$
X_{i}=\left|X_{i}-X_{\text {Light }, i}\right| \cdot e^{\theta} \cdot \cos 2 \pi \theta+X_{i} ; i=G r_{1}+1, \ldots, G r_{1}+G r_{2}
$$

where $\theta$ is a randomlyselected number in range of (-1-(CI/MI),1) [17]; Gr2iscalculated by:

$$
G r_{2}=\operatorname{round}\left(\left(G r-G r_{1}\right) \times\left(1-\frac{C I}{M I}\right)\right)
$$

\subsubsection{Celestial navigation phase:}

In the last phase, Onlookers are divided in two smallgroups. Moths in two small groups are updated their new positions by using the following (13) and (14),

$$
\begin{gathered}
X_{k}=X_{k}+X_{r 6}+\left[R_{1} \cdot X_{b e s t}-R_{2} \cdot X_{k}\right] ; k=G r_{2}+G r_{1}+1, \ldots, G r \\
X_{k}=X_{k}+R_{3} \cdot X_{r 6}+\left(1-\frac{C I}{M I}\right) \cdot R_{4} \cdot\left(X_{\text {ligth }, k}-X_{k}\right)+\left(\frac{2 C I}{M I}\right) \cdot R_{5} \cdot\left(X_{\text {best }}-X_{k}\right) ; \\
\text { with } k=G r_{2}+G r_{1}+1, \ldots, G r
\end{gathered}
$$

\subsection{The implementation of MSA toOCLSD problem}

Two parameters of OCSA problem such as the location and sizing of capacitors are considered as the control variables of MSA. These variables are a solution corresponding to a moth. The process for executing MSA to OCSA problem is described as Figure 1 (see in appendix). Such figure displays the flowchart of MSA.

\section{NUMERICAL RESULTS}

The method applying MSA has been tested on distribution system of 15 buses for solving the optimal capacitor placement problem. The single line diagram of such system and its dataare taken from [5]. The process for calculating MSA method is implemented on a PC with processor Core i5 $-2.2 \mathrm{GHz}$ and 4GB of RAM. In addition, after determining location and size of capacitors, power flow method is applied to calculate branch currents and then power loss is obtained by using (1). Population size and the number of maximum iterationsare set to 30 and 100. Fifty trial runs are implemented for MSA. Total active power loss objective function isemployed to assess the ability of MSA with four differentcases regarding the placementof different location of capacitors. The four cases are described as follows:

- Case 1: Considers aconnection of two capacitorsat two different buses

- Case 2: Investigates an installation of three capacitors at three different buses

- Case 3: Studies the installationof four capacitors at four different buses

- Case 4: Inspects five capacitorsat five different buses.

\subsection{Power loss optimization}

The active power loss of the investigated system is $61.8 \mathrm{~kW}$ [2]. This value can reduce by connecting capacitors. In power loss reduction, the determination of accurate location and suitable size of capacitors has played a very important role. If this process is incorrect, it leads to over compensation. For this reason, MSA has been applied in determining the optimal location and sizing of capacitors. Results obtained by MSA along with other methods for all investigated cases are shown in Tables 1-8. Tables 1-4 show the optimal position and size of capacitors of MSA and other methods. For case 1, the optimal locations found by MSA are bus 4 and bus 6 , those for case 2 are buses 4, 6 and 11. Those for case 3 are buses 4, 6, 9 and 11, and those from case 4 represent buses 4, 6, 7, 9 and 11. The optimal capacitor sizes given by MSA for case 1 are 
$701.65 \mathrm{kVAR}$ and $438.36 \mathrm{kVAR}$, those for case 2 are $488.25 \mathrm{kVAR}, 408.08 \mathrm{kVAR}$ and $300.10 \mathrm{kVAR}$, those for case 3 are $457.09 \mathrm{kVAR}, 377.03 \mathrm{kVAR}, 139.05 \mathrm{kVAR}$ and $284.76 \mathrm{kVAR}$ and those for case 4 are 460.75 kVAR, 156.03 kVAR, 209.75 kVAR, 152.14 kVAR and 284.19 kVAR.

Table 1. The optimum sizing and location of capacitors of methods for case 1

\begin{tabular}{ccccc}
\hline & Bus no & 3 & 4 & 6 \\
\hline & HEM [2] & 805 & 0 & 388 \\
Qc & TVIWPSO [6] & 871 & 0 & 321 \\
(kVAR) & ACO [10] & 0 & 630 & 410 \\
& MSA & 0 & 701.65 & 438.36 \\
\hline
\end{tabular}

Table 2. The optimum sizing and location of capacitors of methods for case 2

\begin{tabular}{cccccccc}
\hline & Bus no & 2 & 4 & 5 & 6 & 11 & 15 \\
\hline \multirow{2}{*}{$\mathrm{Qc}$} & GA [8] & 750 & 0 & 300 & 0 & 150 & 0 \\
$(\mathrm{kVAR})$ & MHA [11] & 0 & 0 & 0 & 350 & 300 & 300 \\
& MSA & 0 & 488.25 & 0 & 408.08 & 300.1 & 0 \\
\hline
\end{tabular}

Table 3. The optimum sizing and location of capacitors of methods for case 3

\begin{tabular}{cccccccc}
\hline \multicolumn{2}{c}{ Bus no } & 4 & 6 & 9 & 11 & 13 & 15 \\
\hline Qc & IWPSO [9] & 450 & 450 & 0 & 0 & 150 & 150 \\
(kVAR) & MSA & 457.09 & 377.03 & 139.05 & 284.76 & 0 & 0 \\
\hline
\end{tabular}

Table 4. The optimum sizing and location of capacitors of methods for case 4

\begin{tabular}{cccccccc}
\hline \multicolumn{2}{c}{ Bus no } & 4 & 6 & 7 & 9 & 11 & 15 \\
\hline \multirow{2}{*}{ Qc } & PSO [4] & 274 & 193 & 143 & 0 & 267 & 143 \\
\multirow{2}{*}{ (kVAR) } & DE [5] & 345 & 264 & 143 & 0 & 300 & 143 \\
& MSA & 460.75 & 156.03 & 209.75 & 152.14 & 284.19 & 0 \\
\hline
\end{tabular}

Tables 5-8 showa comparison between results obtained from MSA and other methods in term of a power loss, a reduction of power loss $(R P L)$ in $\mathrm{kW}$ and in $(\%)$. Column 3 of these tables shows that the power losses value gotten by MSA is always better than other methods for all cases. That of MSA is $32.31 \mathrm{~kW}$ for case $1,30.34 \mathrm{~kW}$ for case $2,29.90 \mathrm{~kW}$ for case 3 and $29.75 \mathrm{~kW}$ for case 4 whilst that of others is from $32.6 \mathrm{~kW}$ to $36.81 \mathrm{~kW}$ for case 1 , from $31.12 \mathrm{~kW}$ to $31.67 \mathrm{~kW}$ for case $2,30.3 \mathrm{~kW}$ for case 3 and from $30.55 \mathrm{~kW}$ to $30.96 \mathrm{~kW}$ for case 4 . As valuing the reduction of power loss, MSA can reach less power loss than other methods by from $0.29 \mathrm{~kW}$ to $4.5 \mathrm{~kW}$ for case 1 , from $0.78 \mathrm{~kW}$ to $1.33 \mathrm{~kW}$ for case $2,0.4 \mathrm{~kW}$ for case 3 and from $0.8 \mathrm{~kW}$ to $1.21 \mathrm{~kW}$ for case 4 . The reduction of power loss corresponding to the improvement percentage of MSA over other ones is presented in column 5 of Tables 5-8. From these comparisons, it can be seen that MSA can reach better optimal result than other methods for all cases. In addition, the voltage at buses is also presented in Figure 2. Such figure shows the improvement of voltages in cases with or without installing capacitors.

Table 5. Comparisonbetween results obtained from MSA and other methods for case 1

\begin{tabular}{ccccc}
\hline Method & Total KVAR added & Power loss kW & RPL In kW & RPL In \% \\
\hline HEM [2] & 1193 & 32.6 & 0.29 & 0.89 \\
TVIWPSO [6] & 1192 & 32.7 & 0.39 & 1.19 \\
ACO [10] & 1040 & 36.81 & 4.5 & 12.22 \\
MSA & 1140 & 32.31 & - & - \\
\hline
\end{tabular}

Table 6. Comparison between results obtained from MSA and other methods for case 2

\begin{tabular}{ccccc}
\hline Method & Total KVAR added & Power loss kW & RPL In kW & RPL In \% \\
\hline GA [8] & 1200 & 31.67 & 1.33 & 4.20 \\
MHA [11] & 950 & 31.12 & 0.78 & 2.51 \\
MSA & 1196.431 & 30.34 & - & - \\
\hline
\end{tabular}

Table 7. Comparison between results obtained from MSA and other methods for case 3

\begin{tabular}{ccccc}
\hline Method & Total KVAR added & Power loss kW & RPLIn kW & RPLIn \% \\
\hline IWPSO [9] & 1200 & 30.3 & 0.4 & 1.32 \\
MSA & 1258 & 29.90 & - & - \\
\hline
\end{tabular}


Table 8. Comparison between results obtained from MSA and other methods for case 4

\begin{tabular}{ccccc}
\hline Method & Total KVAR added & Power loss $(\mathrm{kW})$ & RPL InkW & RPL In \% \\
\hline PSO [4] & 1020 & 30.55 & 0.8 & 2.62 \\
DE [5] & 1195 & 30.96 & 1.21 & 3.91 \\
MSA & 1263 & 29.75 & - & - \\
\hline
\end{tabular}

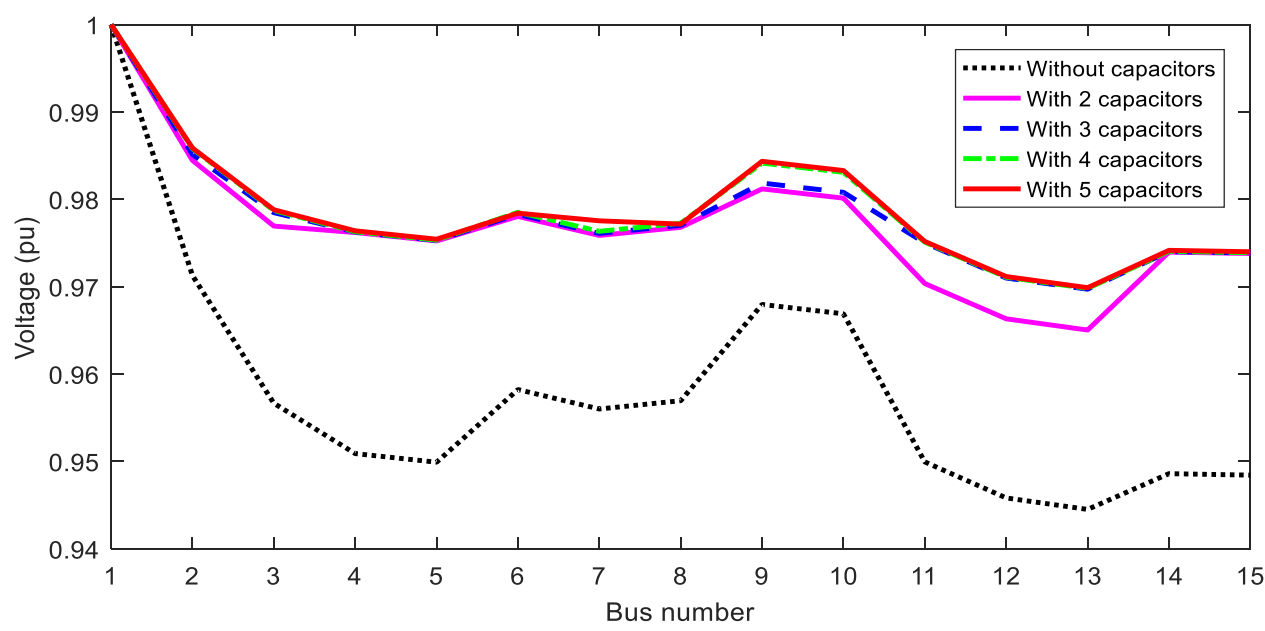

Figure 2. The voltage improvement with and without installing capacitors

\subsection{Discussion}

The number of capacitors installed onto radial distribution system has asignificant impact on reducing the power loss as well as improving the quality of voltages at busesin the radial distribution systems. The selection of capacitor number needs to be calculated and analyzed carefully. For this view, Figures 3 and 4 have been plotted to show analteration of power loss values and improvement of voltages with different numbers of installed capacitors. As shown in Figure 3, the value of power loss decreases from $32.31 \mathrm{~kW}$ to $29.75 \mathrm{~kW}$ corresponding to from case of added two capacitors to case of added four capacitors. On the other hand, Figure sees voltage is also highly improved, namely from 0.965 corresponding to two-capacitor installation to 0.9699 pu corresponding to five-capacitor installation.

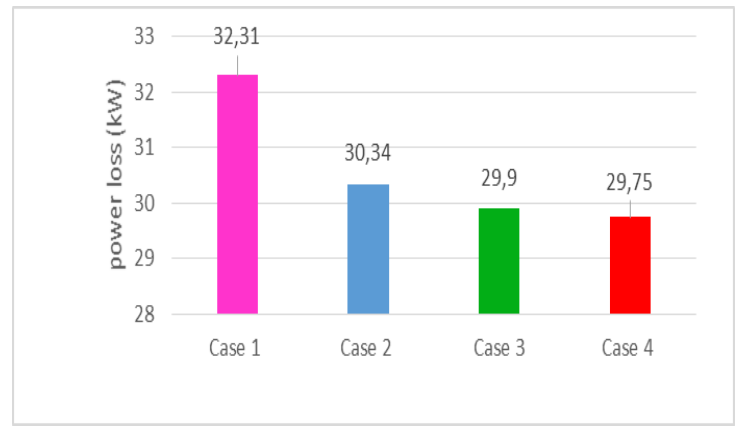

Figure 3. The change of power loss value by adding number of added capacitors

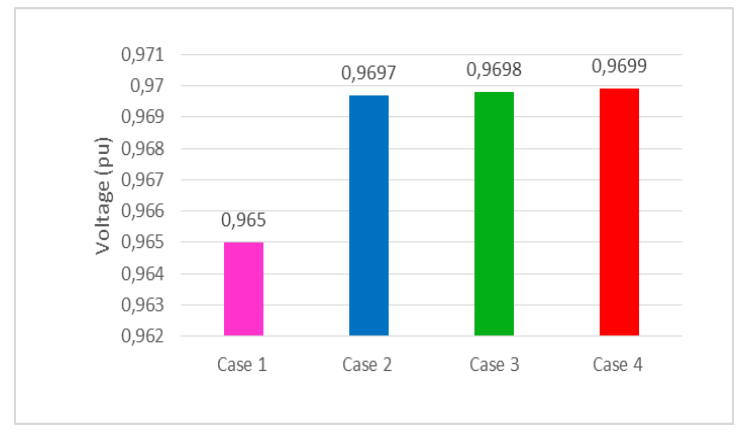

Figure 4. The improvement of voltage by number of added capacitors

\section{CONCLUSION}

In this research, MSA is recommended for determining the position and sizing of capacitors in the standard distribution system with 15 buses. Results from using MSA show that the power losses are downed up $29.49 \mathrm{~kW}$ by adding capacitors at 2 buses, $31.46 \mathrm{~kW}$ by adding capacitors at 3 buses, 31.9 by adding capacitors at 4 buses and $32.05 \mathrm{~kW}$ by adding capacitors at 5 buses. In addition, the voltage at buses compared between uncompensated system and compensated system are also improved. Namely, the voltage improvement is $0.0205 \mathrm{pu}$ for case $1,0.0252 \mathrm{pu}$ for case 2, $0.0253 \mathrm{pu}$ for case 3 and $0.0254 \mathrm{pu}$ for case 4 . In result comparison with other methods, itindicates that MSA can reach better optimal solutions with less 
power loss for all cases. From here, it is possible to infer that the method is an effective method for solving OCLSD problem. In addition, MSA can be applied in future work for determining optimal parameters of STATCOM with the purpose of voltage profile enhancement.

\section{APPENDIX}

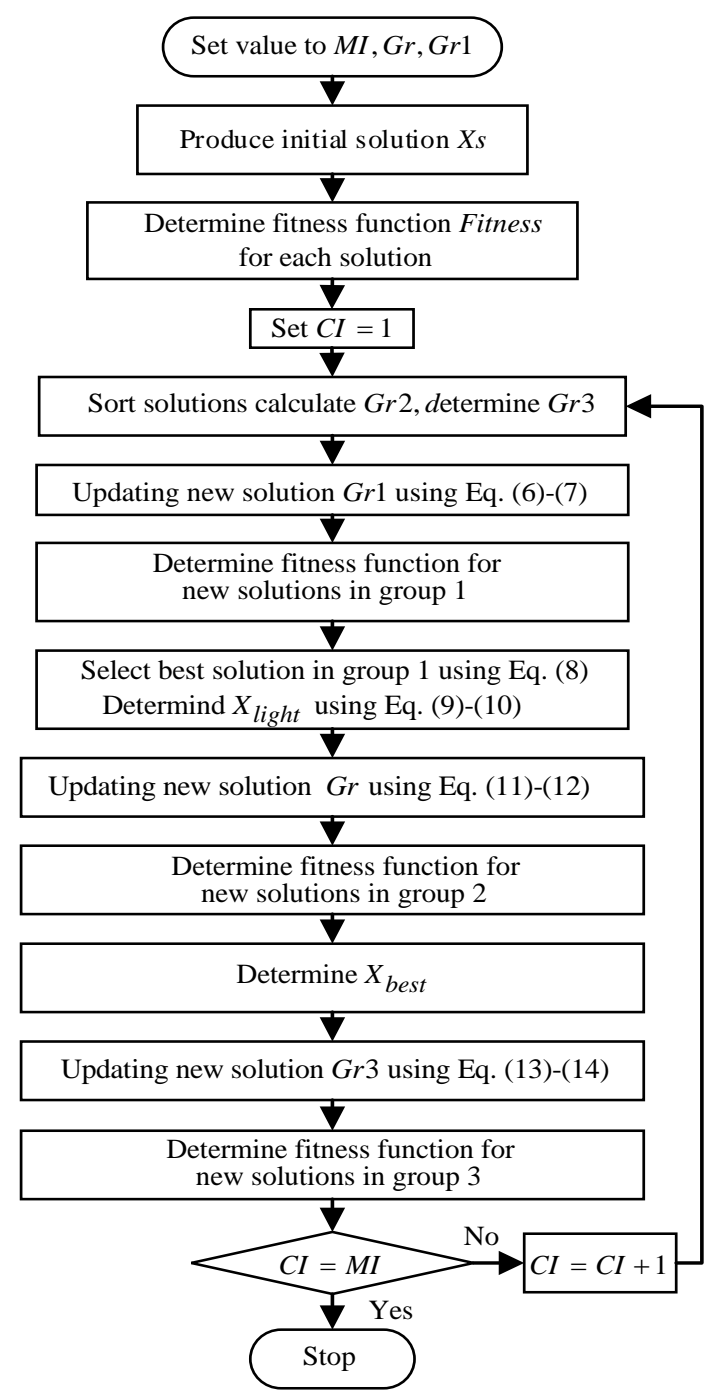

Figure 1. The flowchart of MSA

\section{REFERENCES}

[1] Suliman, M.Y., "Voltage profile enhancement in distribution network using static synchronous compensator STATCOM," International Journal of Electrical and Computer Engineering (IJECE), vol. 10, no. 4, pp. 3367-3374, 2020.

[2] Haque. M.H, "Capacitor placement in radial distribution systems for loss reduction," IEEE ProceedingsGeneration, Transmission and Distribution, vol. 146, no. 5, pp. 501-505, 1999.

[3] Reddy. M.D., "Optimal capacitor placement using fuzzy and real coded genetic algorithm for maximum savings," Citeseer, 2008.

[4] Reddy. M.D. and Reddy. V.V., "Capacitor placement using fuzzy and particle swarm optimization method for maximum annual savings," ARPN Journal of Engineering and Applied Sciences, vol. 3, no. 3, pp. 25-30, 2008.

[5] Kannan S. M., Renuga P., Kalyani. S and Muthukumaran. E, "Optimal capacitor placement and sizing using Fuzzy-DE and Fuzzy-MAPSO methods," Applied Soft Computing, vol. 11, no. 8, pp. 4997-5005, 2011. 
[6] Prakash. K, andSydulu. M, "Particle swarm optimization based capacitor placement on radial distribution systems," IEEE Power Engineering Society General Meeting, pp. 1-5, 2007.

[7] Ali. I, Thomas. M. S, and Kumar, P, "Optimal capacitor placement in smart distribution systems to improve its maximum loadability and energy efficiency," International Journal of Engineering, Science and Technology, vol. 3, no. 8, pp. 271-284, 2011.

[8] Reddy V. V. K and Sydulu M, "Index and GA based optimal location and sizing of distribution system capacitors," IEEE Power Engineering Society General Meeting, pp. 1-4, 2007.

[9] Elsheikh A, Helmy Y, Abouelseoud Y andElsherif A, "Optimal capacitor placement and sizing in radial electric power systems," Alexandria Engineering Journal, vol. 53, no. 4, pp. 809-816, 2014.

[10] El-Ela A. A, Kinawy A. M, Mouwafi M. T and El-Sehiemy R. A, "Optimal sitting and sizing of capacitors for voltage enhancement of distribution systems," 50th International Universities Power Engineering Conference, pp. 1-6, 2015.

[11] Ali. E. S, Elazim. S. A and Abdelaziz. A. Y, "Improved harmony algorithm and power loss index for optimal locations and sizing of capacitors in radial distribution systems," International Journal of Electrical Power and Energy Systems, vol. 80, pp. 252-263, 2016.

[12] El-Fergany. A. A and Abdelaziz. A. Y, "Capacitor placement for net saving maximization and system stability enhancement in distribution networks using artificial bee colony-based approach," International Journal of Electrical Power and Energy Systems, vol. 54, pp. 235-243, 2014.

[13] Sultana. S and Roy. P. K, "Optimal capacitor placement in radial distribution systems using teaching learning based optimization," International Journal of Electrical Power and Energy Systems, vol. 54, pp. 387-398, 2014.

[14] Chiou. J. P and Chang. C. F, "Development of a novel algorithm for optimal capacitor placement in distribution systems," International Journal of Electrical Power and Energy Systems, vol. 73, pp. 684-690, 2015.

[15] Lee. C. S, Ayala. H. V. H and dos Santos Coelho. L, "Capacitor placement of distribution systems using particle swarm optimization approaches," International Journal of Electrical Power and Energy Systems, vol. 64, pp. 839-851, 2015.

[16] Tamilselvan V., Jayabarathi T., Raghunathan T. and Yang X.S., "Optimal capacitor placement in radial distribution systems using flower pollination algorithm," Alexandria Engineering Journal, vol. 57, no. 4, pp. 2775-2786, 2018.

[17] Khormandichali, S. M. M., and Kamarposhti, M. A, "Optimal placement of wind generation units in order to increase revenues and reduce the imposed costs in the distribution system considering uncertainty," International Journal of Electrical and Computer Engineering, vol. 9, no. 6, pp. 4524-4539, 2019.

[18] Garfi, O., Aloui, H., Chaker, N, "Impacts of photovoltaic power source intermittence on a distribution network," International Journal of Electrical and Computer Engineering (IJECE), vol. 9, no. 6, pp. 5134-5142, 2019.

[19] Reddy, A. S., Reddy, M. D., and Reddy, M. S. K, "Network reconfiguration of primary distribution system using GWO algorithm," International Journal of Electrical and Computer Engineering (IJECE), vol. 7, no. 6, pp. 3226-3234, 2017.

[20] Firdaus, A. A., Penangsang, O., and Soeprijanto, A, "Distribution network reconfiguration using binary particle swarm optimization to minimize losses and decrease voltage stability index," Bulletin of Electrical Engineering and Informatics, vol. 7, no. 4, pp. 514-521, 2018.

[21] Mohammedi, R. D., Zine, R., Mosbah, M., and Arif, S, "Optimum network reconfiguration using grey wolf optimizer," TELKOMNIKA (Telecommunication, Computing, Electronics and Control), vol. 16, no. 5, pp. 2428-2435, 2018.

[22] Raj, A., Ab Aziz, N. F., Yasin, Z. M., and Salim, N. A, "Investigation of distributed generation units placement and sizing based on voltage stability condition indicator (VSCI)," International Journal of Power Electronics and Drive Systems (IJPEDS), vol. 10, no. 3, pp. 1317-1323, 2019.

[23] Mohamed. A. A. A, Mohamed. Y. S, El-Gaafary. A. A andHemeida. A. M, "Optimal power flow using moth swarm algorithm," Electric Power Systems Research, vol. 142, pp. 190-206, 2017.

[24] Jevtic. M, Jovanovic. N, Radosavljevic. J and Klimenta. D, "Moth swarm algorithm for solving combined economic and emission dispatch problem," Elektronikair Elektrotechnika, vol. 23, no. 5, pp. 21-28, 2017.

[25] Zhou. Y, Yang. X, Ling. Y and Zhang J, "Meta-heuristic moth swarm algorithm for multilevel thresholding image segmentation," Multimedia Tools and Applications, vol. 77, no. 18, pp. 23699-23727, 2018.

[26] Jaiswal, V., Sharma, V., and Varma, S, "MMFO: modified moth flame optimization algorithm for region based RGB color image segmentation," International Journal of Electrical and Computer Engineering (IJECE), vol. 10, no. 1, pp. 196-204, 2020. 